\title{
Comment on 'The Contribution of National Spontaneous Reporting Systems to Detect Signals of Torsadogenicity: Issues Emerging from the ARITMO Project'
}

\author{
Alain Braillon ${ }^{1}$
}

Published online: 19 February 2016

(c) Springer International Publishing Switzerland 2016

Raschi et al. [1] extracted torsade de pointes-related events from three national spontaneous reporting systems (SRSs) and found five potential signals undetected in the US Food and Drug Administration (FDA) Adverse Event Reporting System. However, they should also have highlighted what signals they did not find.

Indeed, the absence of reports for citalopram or escitalopram and for thioridazine (which was withdrawn from the market worldwide only in 2005) is surprising, as they should rank among the top ones [2, 3].

Similarly, in an analysis of drug-induced pancreatitis, using the French SRS, the lack of a report for amiodarone was unnoticed despite this drug being widely used and its imputability being well evidence based [4-6].

Such 'no findings' are an opportunity to call, once more, for raising the bar for drug safety. This needs a comprehensive framework: better education and training, incentives for reporting, selective reports versus exhaustive reporting (e.g. seriousness, drug class and timeframe) and access to electronic health records (disease, hospitalization and prescriptions) for researchers, etc. The list is long and not new, as is the inertia of the system.

Compliance with Ethical Standards

Funding No sources of funding were used in the preparation of this letter.

Conflict of interest Alain Braillon has no conflicts of interest that are directly relevant to the content of this letter.

Alain Braillon

braillon.alain@gmail.com

University Hospital, Amiens, France

\section{References}

1. Raschi E, Poluzzi E, Salvo F, et al. The contribution of national spontaneous reporting systems to detect signals of torsadogenicity: issues emerging from the ARITMO Project. Drug Saf. 2016;39: $59-68$.

2. Maljuric NM, Noordam R, Aarts $\mathrm{N}$, et al. Use of selective serotonin re-uptake inhibitors and the heart rate corrected QT interval in a real-life setting: the population-based Rotterdam Study. Br J Clin Pharmacol. 2015;80:698-705.

3. Berling I, Isbister GK. Prolonged QT risk assessment in antipsychotic overdose using the QT nomogram. Ann Emerg Med. 2015;66:154-64.

4. Chebane L, Bagheri H, Hillaire-Buys D, et al. Pancréatites d'origine médicamenteuse: revue des notifications spontanées en France. Rev Med Intern. 2015;36:573-8.

5. Alonso A, MacLehose RF, Lutsey PL, et al. Association of amiodarone use with acute pancreatitis in patients with atrial fibrillation: a nested case-control study. JAMA Intern Med. 2015;175:449-50.

6. Lai SW, Lin CL, Liao KF, et al. Amiodarone use and risk of acute pancreatitis: a population-based case-control study. Heart Rhythm. 2015;12:163-6. 